Malaysian Journal of Social Sciences and Humanities (MJSSH)

Volume 4, Issue 7, November 2019

e-ISSN : 2504-8562

Journal home page:

www.msocialsciences.com

\title{
Kesan Penggunaan Sumber-Sumber Dokumen Teks Sejarah Terhadap Kefahaman Konsep Substantif Sejarah
}

\author{
M. Kaviza ${ }^{1}$ \\ 1Pusat Pengajian Pendidikan dan Bahasa Moden, Universiti Utara Malaysia (UUM) \\ Correspondence: M. Kaviza (kavizakaviza@yahoo.com)
}

\begin{abstract}
Abstrak
Kajian ini bertujuan mengkaji kesan penggunaan sumber-sumber dokumen teks sejarah terhadap kefahaman konsep substantif sejarah dalam kalangan murid Tingkatan Empat. Dalam kajian ini, sebuah modul pengajaran telah dibangunkan sebagai intervensi penggunaan sumber-sumber dokumen teks sejarah. Reka bentuk Pra-eksperimen iaitu Ujian Pra-Ujian Pasca Satu Kumpulan telah digunakan dalam kajian ini. Kesan penggunaan sumber-sumber dokumen teks sejarah terhadap kefahaman konsep substantif sejarah diukur dalam ujian pra, ujian pasca dan ujian pasca lanjutan. Seramai 55 orang murid yang ditentukan dengan menggunakan teknik cluster sampling daripada kelas sedia ada terlibat sebagai sampel dalam kajian ini. Ujian kefahaman konsep substantif sejarah telah digunakan dalam kajian ini. Data telah dianalisis secara deskriptif dan inferensi iaitu ujian ANOVA Satu Hala dengan Pengukuran Berulang. Dapatan kajian menunjukkan bahawa penggunaan sumber-sumber dokumen teks sejarah memberi kesan peningkatan dan kekekalan kepada kefahaman konsep substantif sejarah. Implikasi kajian ini adalah dalam menyediakan kandungan dan pelaksanaan strategi pembelajaran sejarah dengan menggunakan satu set koleksi sumber-sumber dokumen teks sejarah yang relevan dalam topik pelajaran sejarah.
\end{abstract}

Kata kunci: kefahaman konsep substantif sejarah, pembelajaran sejarah, sumber-sumber dokumen teks sejarah

\section{The Impact of Using Historical Text Document Resources on the Understanding of Historical Substantive Concepts}

\begin{abstract}
This study aims at investigating the effect of using historical text document resources on the historical substantive concepts understanding among Form Four students. A learning activities module was developed based on using historical text document resources as reference for intervention in this study. Pre-Experimental Design: One Group PreTest-PostTest was used in this study. The impact of using historical teks document resources on the historical substantive concepts understanding were measured in the pre-test, post-test and delayed post-test. A sample of respondents comprising 55 students from existing classes was recruited in this study using cluster sampling techniques. The historical substantive concept understanding test was used in this study. Data were analyzed by descriptive and inference statistics using Repeated-Measures One Way ANOVA test. The findings showed that the use of historical text document resources has an impact on the historical substantive concepts understandingand retaintion. The implication of this study is to provide the content and methods for
\end{abstract}


implementation of history learning by using a set of collections of historical text document resources which relevant to a historical topic.

Keywords: history learning, historical document resources, historical sustantive concepts understanding

\section{Pengenalan}

Penggunaan sumber-sumber dokumen teks sejarah tidak dapat dipisahkan daripada proses pengkajian sejarah (Cowgill II \& Waring, 2017; Wineburg, 1991; 2001). Kemajuan teknologi maklumat telah membawa inovasi dalam kaedah pengajaran sejarah sedia ada dengan membuat pengubahsuaian kepada teknik dan bahan pengajaran yang dapat menggalakkan penglibatan aktif dalam kalangan murid. Dalam konteks pendidikan sejarah di Malaysia, sukatan pelajaran sejarah dalam Kurikulum Bersepadu Sekolah Menengah (KBSM) dan Kurikulum Standard Sekolah Menengah (KSSM) telah mengariskan struktur disiplin sejarah yang menekankan pengumpulan sumber sebagai salah satu komponen utama dalam struktur disiplin tersebut (Pusat Perkembangan Kurikulum (PPK), 2003, 2015) seperti ditunjukkan pada Rajah 1. Komponen pengumpulan sumber pada asasnya mementingkan pengkayaan dan penerokaan sumber-sumber sejarah dalam kalangan murid. Sehubungan dengan itu, para murid perlu didedahkan tentang tatacara mendapatkan sumber, punca-punca sumber, pengkelasan sumber primer dan sumber sekunder dan seterusnya merekod bukti-bukti yang diperolehi daripada sumber-sumber sejarah tersebut (PPK, 2003; 2015). Secara umumnya, sumber-sumber dokumen teks sejarah merujuk kepada bahan dalam bentuk tulisan yang dapat menjelaskan tentang sesuatu peristiwa sejarah yang telah berlaku pada masa lepas.

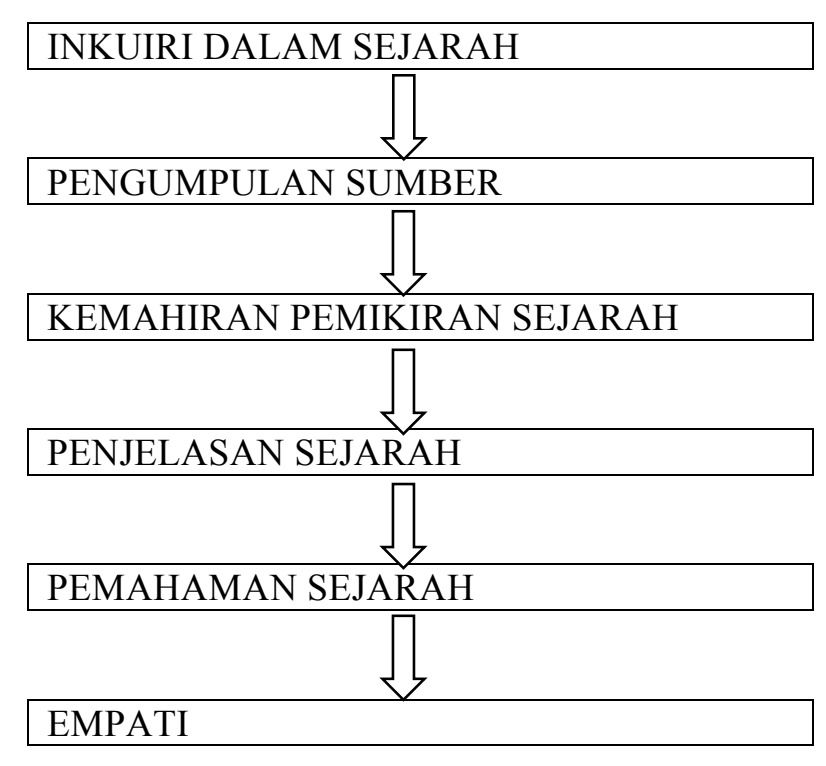

Rajah 1: Struktur Disiplin Sejarah Sumber: PPK, (2003)

Kefahaman sejarah ditakrifkan sebagai kebolehan merefleksi, mensintesis dan mengkonstruk penguasaan sejarah berdasarkan bukti sejarah (Haydn, Arthur, Hunt, 2001; Foster, 2013). Kefahaman sejarah membolehkan murid meneroka fakta baru bagi menjelaskan sesuatu peristiwa sejarah dengan menggalakkan proses penyelidikan sejarah. Oleh itu, proses penyelidikan sejarah memerlukan murid menganalisis bukti sejarah bagi membina kefahaman terhadap konsep-konsep dan peristiwa sejarah yang telah berlaku (Wineburg, 2001; Stoskopf \& Bermudez, 2008; Rogers, 2008; Lee, 2005). Dalam konteks kurikulum sejarah, konsep substantif sejarah menjadi teras dan kerangka dalam mengorganisasikan maklumat yang lepas dalam disiplin sejarah yang melibatkan konteks-konteks tertentu (Seixas, 1993; McCrory, 2017; Hammond, 2014). Adalah diakui bahawa konsep merupakan imej mental yang digunakan untuk mengkonstruk sesuatu realiti bagi menjelaskan kefahaman 
seseorang secara kronologi disebabkan oleh sifat disiplin sejarah itu sendiri yang dipandu berdasarkan konsep-konsep tertentu (Crick \& Porter, 1978; Heater, 1974; Haenen \& Schrijinemakers, 2000). Proses kefahaman konsep substantif sejarah yang melibatkan menngkategorikan konsep secara berurutan, memindahkan konsep ke dalam konteks yang lain, membolehkan pembinaan makna atau maksud tertentu, dan dapat digabungjalinkan dengan konsep yang lain adalah selaras dengan pendapat Bruner (1960) yang telah mengungkapkan bahawa murid boleh belajar dalam pelbagai tahap dalam meningkatkan kefahaman mereka. Hal ini kerana konsep substantif sejarah melihatkan sesuatu perkara dalam pelbagai aspek iaitu dari segi aspek politik, ekonomi, sosial dan lain-lain dalam mengolah sesuatu kefahaman serta membezakan antara peristiwa dengan masa secara khususnya (Lee, 2005, 2011; Vansledright, 2014). Justeru, konsep substantif sejarah amat penting dalam proses pengajaran dan pembelajaran di dalam kelas.

\section{Pernyataan Masalah}

Walaupun kefahaman konsep substantif sejarah merupakan sesuatu yang unik dalam disiplin sejarah, namun murid-murid didapati tidak dapat memahami konsep-konsep tersebut disebabkan sifat yang berbentuk teoritikal dan abstrak yang memerlukan murid untuk menerangkan dalam peristiwa secara konkrit dari aspek objek, orang, dan lain lagi (Lee, 2005; Van Drie \& Van Boxtel, 2003; Berti \& Vanni, 2000). Hal ini kerana kefahaman konsep melibatkan dimensi konkrit-abstrak yang saling berkait dalam suatu situasi yang kompleks merentasi konteks masa yang berbeza-beza.Tambahan pula, limitasi dalam penerokaan sumber-sumber dokumen juga telah menjadi salah satu faktor penyebab kegagalan kefahaman konsep substantif sejarah dalam kalangan murid disebabkan oleh mereka dapat memahami maklumat dengan terperinci (Cutajar, 2013; Breakstone \& Smith, 2013; Hover, Hicks \& Dack, 2016; Nokes, 2014; Reisman, 2012). Pendapat ini adalah seiring dengan tinjauan analisis keperluan kajian yang dilakukan oleh pengkaji dalam kajian ini yang telah mendapati bahawa tahap pengetahuan, kemahiran dan sikap dalam penerokaan dan penggunaan sumber-sumber di dalam kelas berada pada tahap sederhana dan hampir 70 peratus murid turut melaporkan bahawa mereka tidak minat dengan mata pelajaran sejarah serta telah mencadangkan perubahan dalam strategi pengajaran dan pembelajaran mereka (Kaviza, 2018). Sehubungan dengan itu, penerokaan sumber-sumber dokumen teks sejarah merupakan suatu cadangan dalam menyahut perubahan tersebut disebabkan pelaksanaannya adalah diharapkan berpotensi untuk meningkatkan kebolehan murid dalam memahami konsep-konsep subatantif sejarah (Nokes, 2014; Barton, 2005; Counsell, 2000; Levesque, 2010). Maka, kajian ini bertujuan untuk mengkaji kesan penggunaan sumber-sumber dokumen teks sejarah terhadap kefahaman konsep substantif sejarah dalam kalangan murid.

\section{Objektif Kajian}

Kajian ini adalah untuk menjawab objektif kajian berikut:

i. Mengenal pasti sama ada penggunaan sumber-sumber dokumen teks sejarah berkesan terhadap kefahaman konsep substantif sejarah.

ii. Mengenal pasrti sama ada penggunaan sumber-sumber dokumen teks sejarah berkesan terhadap kekekalan kefahaman konsep substantif sejarah.

\section{Soalan Kajian}

Kajian ini adalah untuk menjawab soalan kajian berikut:

i. Adakah penggunaan sumber-sumber dokumen teks sejarah berkesan ke atas kefahaman konsep substantif sejarah?

ii. Adakah penggunaan sumber-sumber dokumen teks sejarah berkesan ke atas kekekalan kefahaman konsep substantif sejarah? 


\section{Hipotesis Kajian}

Satu hipotesis nul $\left(\mathrm{H}_{\mathrm{ol}}\right)$ telah dibentuk bagi menjawab persoalan kajian 1 dan 2 iaitu:

$\mathrm{H}_{\mathrm{ol}}$ : Tidak terdapat kesan utama yang signifikan bagi siri ujian terhadap min kefahaman konsep substantif sejarah bagi murid yang menggunakan sumber-sumber dokumen teks sejarah.

$\mathrm{Ho}_{1 \mathrm{a}}$ : Tidak terdapat perbezaan yang signifikan antara ujian pra dan ujian pasca terhadap min kefahaman konsep substantif sejarah bagi murid yang menggunakan sumber-sumber dokumen teks sejarah.

$\mathrm{Ho}_{1 \mathrm{~b}}$ :Tidak terdapat perbezaan yang signifikan antara ujian pasca dan ujian lanjutan terhadap min kefahaman konsep substantif sejarah bagi murid yang menggunakan sumber-sumber dokumen teks sejarah.

\section{Sorotan Kajian}

Disiplin sejarah merupakan kajian terhadap himpunan bahan-bahan peninggalan masa silam yang digunakan oleh sejarahwan sebagai bahan bukti sejarah, khususnya sumber-sumber dokumen teks sejarah bagi membuktikan interpretasi mereka mengenai peristiwa yang telah berlaku pada masa silam (Hazri, Jamil, 2003; Hover et al, 2016; Wineburg, 1991). Proses pengkajian sejarah adalah berkaitan dengan memahami, menilai, menganalisis dan menginterpretasikan sumber-sumber dokumen teks sejarah yang dijadikan bukti kepada penjelasan yang dibuat tentang perkara dan peristiwa masa silam. Sumber-sumber dokumen teks sejarah sebagai sebuah karya yang menyediakan maklumat atau bukti yang bersifat asli yang berkaitan dengan sesuatu fakta, kejadian atau siri sesuatu peristiwa yang telah berlaku pada masa lalu yang telah dijadikan sebagai bahan kajian oleh sejarahwan (Suntralingam, 1985). Terdapat dua jenis sumber-sumber dokumen teks sejarah iaitu sumber primer dan sumber sekunder. Sumber primer merujuk kepada sumber-sumber seperti catatan, laporan, surat, buku harian, dokumen, rekod dan sebagainya yang bersifat asli yang dapat memberikan maklumat, catatan atau melaporkan mengenai sesuatu peristiwa yang telah berlaku. Manakala, sumber sekunder pula dirujuk sebagai sumber yang tidak asli yang dihasilkan oleh sejarahwan melalui penulisan mereka tentang sesuatu peristiwa sejarah yang berpandukan kepada sumber primer seperti enskliopedia, majalah, buku teks, risalah dan sebagainya (Hazri Jamil, 2003; Library of Congress, 2019; Newmann, 2001).

Namun begitu, penggunaan sumber-sumber dokumen teks sejarah di dalam kelas adalah masih terhad (Renuka \& Siti, 2012; Wineburg, 1991). Hal ini kerana guru-guru sejarah bergantung sepenuhnya kepada penggunaan buku teks yang menjadi sumber rujukan utama di dalam kelas (Siti Hawa Abdullah, 2008) yang telah menyebabkan murid-murid tidak dapat meneroka sumber-sumber dokumen teks sejarah yang lain bagi meningkatkan pemahaman mereka terhadap sesuatu peristiwa sejarah dengan lebih mendalam (Cowgill II, 2014; Hynd, 1999; Newmann, 2001). Penggunaan sumber-sumber dokumen teks sejarah dalam proses pengajaran dan pembelajaran merupakan perubahan kepada strategi dan kaedah pengajaran sejarah yang bersifat konvensional yang berpusatkan guru. Dengan kemajuan teknologi dan pendigitalan sumber-sumber dokumen teks sejarah, maka guru-guru sejarah adalah berupaya untuk mengakses, memuat turun pelbagai jenis sumber-sumber dokumen teks sejarah melalui laman web sejarah agar dapat digunakan dalam proses pengajaran dan pembelajaran sejarah di dalam kelas (Breakstone \& Smith, 2013; Brown \& Dotson, 2007; Huistra \& Mellink, 2016). Oleh itu, murid-murid berpeluang untuk mengkaji sumber-sumber dokumen teks sejarah dengan membuat interpretasi dan tafsiran sejarah berdasarkan bahan bukti sejarah bagi meningkatkan pemahaman sejarah, disamping dapat meningkatkan kemahiran berfikir dalam kalangan murid seperti disarankan dalam kurikulum sejarah (Macedo-Rouet, Braasch, Britt \& Rouet, 2013; Merkt, Werner \& Wagner, 2017; Reisman, 2012; Reisman, \& Fogo, 2016).

Amalan strategi dan kaedah pengajaran merupakan salah satu kekangan dalam peningkatan penguasaan kandungan kurikulum sejarah. Hal ini kerana keberkesananan sesuatu kaedah penyampaian pembelajaran adalah bergantung kepada pemantapan ilmu dan identiti mata pelajaran sejarah itu 
sendiri. Daya kreativiti dan imaginasi yang baik dapat diperkembangkan dalam kalangan murid melalui pelaksanaan kaedah pengajaran yang sesuai dan relevan. Kaedah pengajaran sejarah yang bersifat sehala yang berpusatkan guru telah menyebabkan murid-murid berasa cepat bosan dan jemu terhadap proses pembelajaran mata pelajaran sejarah di dalam kelas (Azwan Ahmad, Abdul Ghani Kaneson Abdullah, Mohammad Zohir Ahmad \& Abdul Rahman Abdul Aziz, 2005; Abdul Razaq Ahmad, Mohd Mahzan Awang, Ahmad Ali Seman, Ramle Abdullah, 2013; Omardin Haji Ashaari \& Yunus Muhammad, 1996, Abdul Rahim Abdul Rashid, 1999; Mohd Mahzan Awang et al, 2016). Justeru, strategi dan kaedah pengajaran dan pembelajaran mata pelajaran sejarah berasaskan penggunaan sumber-sumber dokumen teks sejarah telah membawa impak positif terhadap proses pembelajaran sejarah dari aspek peningkatan minat belajar sejarah, penguasaan pengetahuan dan kemahiran sejarah (Nokes, 2014; Rantala \& Van den Berg, 2015; Hover et al, 2016; Macedo-Rouet, Braasch, Britt, \& Rouet, 2013; Reisman, 2012; Breakstone \& Smith, 2013; Britt, \& Rouet, 2011).

\section{Metod Kajian}

Kajian ini melibatkan rekabentuk Pra-eksperimen iaitu Ujian Pra-Ujian Pasca Satu Kumpulan (PreExperimental Design: One Group Pretest-Posttest Design) (Cohen, Manion \& Morrison, 2007) iaitu murid diukur dalam ujian pra, murid diberikan rawatan, ujian pasca dijalankan dengan mengukur perbezaan skor min ujian pra dan ujian pasca. Pengukuran ujian lanjutan pula dijalankan pada minggu keempat selepas ujian pasca bagi mengenal pasti sama ada masih terdapat kesan rawatan terhadap variabel bersandar (Campbell dan Stanley, 1963). Kajian ini melibatkan 55 orang murid Tingkatan Empat dari sebuah sekolah menengah harian di sebuah negeri di utara Semenanjung Malaysia yang mempunyai latar belakang dan sosioekonomi yang sama serta mempunyai pencapaian yang setara dalam mata pelajaran sejarah dalam Pentaksiran Tingkatan Tiga (PT3) pada tahun sebelumnya. Pemilihan sampel kajian dalam kajian ini dilakukan secara teknik cluster sampling dengan menggunakan empat buah kelas sedia ada di sekolah tersebut. Instrumen yang digunakan dalam kajian ini ialah ujian kefahaman konsep sejarah yang dibina oleh pengkaji yang telah disahkan oleh dua orang pakar penilai dalam bidang sejarah serta mempunyai nilai kebolehpercayaan K20 iaitu 0.89 yang dianggap baik dan boleh digunakan bagi tujuan kajian ini (Nunnally, 1978). Selain itu, pengkaji juga telah menentukan nilai kesukaran dan diskriminasi item bagi instrumen tersebut dan dilaporkan mempunyai nilai yang boleh digunakan untuk tujuan kajian ini (Nitko, 2004).

\section{Analisis Dapatan Kajian}

Bagi menguji hipotesis pada aras kesignifikan $p=0.05$, maka ujian inferensi ANOVA Satu Hala dengan Pengukuran Berulang telah dijalankan. Jadual 3 menunjukkan min ujian pasca kefahaman konsep substantif sejarah $(M=20.19, S D=3.37)$ lebih tinggi berbanding dengan min skor ujian pra $(M=10.25$, $S D=4.02)$ dan ujian lanjutan $(M=16.38, S D=3.66)$.

Jadual 3: Statistik Deskriptif untuk Min Kefahaman Konsep Sejarah dalam Ujian Pra, Ujian Pasca dan Ujian Lanjutan

\begin{tabular}{llll}
\hline & Ujian Pra & Ujian Pasca & Ujian Lanjutan \\
\hline $\mathrm{N}$ & 55 & 55 & 55 \\
Min & 10.25 & 20.18 & 16.38 \\
Sisihan Piawai & 4.02 & 3.37 & 3.66 \\
\hline
\end{tabular}

Keputusan ujian Multivariate pada Jadual 4 menunjukkan bahawa kesan utama siri ujian terhadap kefahaman konsep substantif sejarah adalah signifikan (Wilks Lambda $=0.21, F(2,53)=42102.92$, $\mathrm{p}<0.05$, eta separa kuasa dua, $\pi^{2}=0.87$ dengan kuasa cerapan 1.00). Nilai eta separa kuasa dua, $\pi^{2}=$ 0.87 dalam kajian ini menunjukkan bahawa saiz kesan siri ujian terhadap kefahaman konsep substantif sejarah adalah sangat besar (Cohen, 1988). Di samping itu, keputusan ujian kesferaan Mauchly yang tidak signifikan dengan nilai $p=0.52$ menunjukkan bahawa andaian kesferaan matriks varian kovarian 
dipatuhi dalam kajian ini. Maka, ujian univariate (Jadual 5) mendapati bahawa kesan utama siri ujian adalah signifikan bagi kefahaman konsep substantif sejarah $\left(F=112.37, \mathrm{p}<0.05, \pi^{2}=0.68\right)$.

Jadual 4: Keputusan Ujian Multivariate untuk Min Kefahaman Konsep Substantif Sejarah

\begin{tabular}{lllllllll}
\hline Kesan & Nilai & $\boldsymbol{F}$ & $\begin{array}{l}\text { Hipotesis } \\
\boldsymbol{d f}\end{array}$ & $\begin{array}{l}\text { Ralat } \\
\boldsymbol{d f}\end{array}$ & $\boldsymbol{p}$ & $\begin{array}{l}\text { Separa } \\
\text { Eta Kuasa } \\
\text { Dua }\end{array}$ & $\begin{array}{l}\text { Kuasa } \\
\text { Cerapan }\end{array}$ \\
\hline Konsep & $\begin{array}{l}\text { Wilks' } \\
\text { Lambda }\end{array}$ & 0.21 & 102.92 & 2.00 & 53.00 & 0.00 & 0.80 & 1.00 \\
\hline
\end{tabular}

Jadual 5: Keputusan Ujian Univariate untuk Min Kefahaman Konsep Substantif Sejarah

\begin{tabular}{lllllllll}
\hline Kesan & & $\begin{array}{l}\text { Jumlah } \\
\text { kuasa Dua } \\
\text { Jenis III }\end{array}$ & $\begin{array}{l}\text { Kf } \\
\text { dua } \\
\text { min }\end{array}$ & F & $\boldsymbol{p}$ & $\begin{array}{l}\text { Separa } \\
\text { Eta } \\
\text { Kuasa } \\
\text { Dua }\end{array}$ & $\begin{array}{l}\text { Kuasa } \\
\text { Cerapan }\end{array}$ \\
\hline Konsep & $\begin{array}{l}\text { Andaian } \\
\text { dipatuhi }\end{array}$ & 2759.79 & 2 & 1379.90 & 112.37 & 0.00 & 0.68 & 1.00 \\
\hline
\end{tabular}

Keputusan ujian multivariate dan univariate yang signifikan $(\mathrm{p}<0.05)$ menunjukkan bahawa terdapat sekurang-kurangnya satu pasangan siri ujian yang mempunyai perbezaan min kefahaman konsep substantif sejarah. Maka, ujian Post Hoc Bonferroni dijalankan untuk menentukan pasangan siri ujian yang mempunyai perbezaan yang signifikan. Berdasarkan Jadual 6, dapatan menunjukan bahawa terdapat perbezaan yang signifikan $(\mathrm{p}<0.05)$ pada pasangan siri ujian iaitu ujian pra, ujian pasca dan ujian lanjutan terhadap min kefahaman konsep substantif sejarah. Oleh itu, hipotesis nol $\mathrm{H}_{\mathrm{ol}}$ dan sub hipotesis nol $\left(\mathrm{H}_{\mathrm{ola}}\right.$ dan $\left.\mathrm{H}_{\mathrm{olb}}\right)$ berjaya ditolak iaitu terdapat kesan utama yang signifikan bagi siri ujian (ujian pra, ujian pasca dan ujian lanjutan) terhadap min kefahaman konsep substantif sejarah dan kekekalan bagi murid yang menggunakan sumber-sumber dokumen teks sejarah. Secara kesimpulannya, peningkatan yang signifikan pada min kefahaman konsep substantif sejarah selepas menjalani rawatan yang menunjukkan bahawa terdapat kesan rawatan iaitu penggunaan sumbersumber dokumen teks sejarah adalah berkesan dalam meningkatkan kefahaman konsep substantif sejarah dalam kalangan murid Tingkatan Empat. Tambahan pula, terdapat sedikit penurunan pada ujian lanjutan kefahaman konsep substantif sejarah selepas tempoh rawatan turut mendapati bahawa terdapat kesan jangka pendek terhadap penguasaan kefahaman konsep sejarah yang berterusan yang disebabkan oleh kesan rawatan yang telah dijalankan dalam kajian ini.

Jadual 6: Keputusan Ujian Post Hoc Bonferroni untuk min Kefahaman Konsep Substantif Sejarah (Pairwise Comparison)

\begin{tabular}{|c|c|c|c|c|c|c|}
\hline & & $\begin{array}{l}\text { Perbezaan } \\
\text { Min }\end{array}$ & Ralat & $p$ & $\begin{array}{l}95 \% \\
\text { keyakinan } \\
\text { perbezaan } \\
\text { Bawah } \\
\end{array}$ & $\begin{array}{r}\begin{array}{r}\text { selang } \\
\text { bagi }\end{array} \\
\text { Atas } \\
\end{array}$ \\
\hline \multirow[t]{2}{*}{ Ujian Pra } & Ujian Pasca & -9.93 & 0.69 & 0.00 & -11.62 & -8.24 \\
\hline & Ujian Lanjutan & -6.13 & 0.70 & 0.00 & -7.86 & -4.40 \\
\hline \multirow[t]{2}{*}{ Ujian Pasca } & Ujian Pra & 9.93 & 0.69 & 0.00 & 8.24 & 11.62 \\
\hline & Ujian Lanjutan & 3.80 & 0.62 & 0.00 & 2.28 & 5.32 \\
\hline \multirow{2}{*}{ Ujian Lanjutan } & Ujian Pra & 6.13 & 0.70 & 0.00 & 4.40 & 7.86 \\
\hline & Ujian Pasca & -3.80 & 0.62 & 0.00 & -5.32 & -2.29 \\
\hline
\end{tabular}

Berdasarkan estimated marginal means

*Perbezaan min adalah signifikan pada aras 0.05 


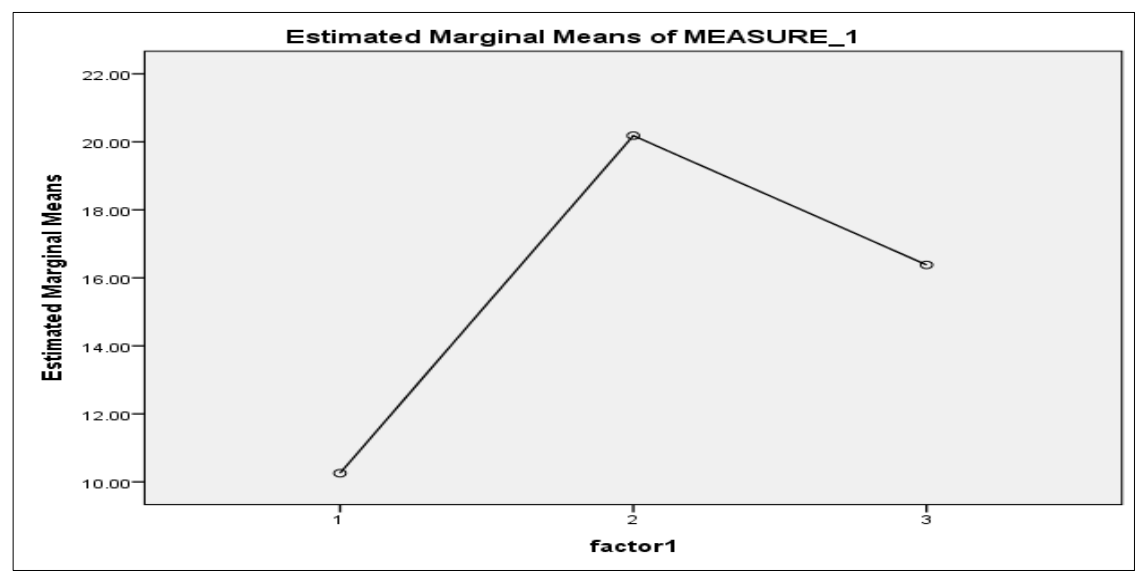

Rajah 2: Graf Plot

\section{Perbincangan Kajian}

Dapatan kajian ini telah menunjukkan bahawa penggunaan sumber-sumber dokumen teks sejarah memberi kesan yang positif terhadap peningkatan dan kekekalan kefahaman konsep substantif sejarah dalam kalangan murid Tingkatan Empat. Dapatan ini adalah selaras dengan dapatan kajian-kajian lepas yang telah menjelaskan bahawa penggunaan sumber-sumber dokumen teks sejarah dapat meningkatkan pemahaman sejarah, di samping dapat meningkatkan kemahiran berfikir dalam kalangan murid (Cowgill II \& Waring, 2017; Reisman, 2012). Hal ini kerana penggunaan sumber-sumber dokumen teks sejarah dalam proses pengajaran dan pembelajaran sejarah merupakan suatu inovasi dalam kaedah pengajaran sedia ada yang dapat meningkatkan kefahaman konsep-konsep substantif sejarah dalam mata pelajaran sejarah (Barton, 2005; Macedo-Rouet, Braasch, Britt \& Rouet, 2013). Dapatan kajian ini juga telah menjelaskan bahawa terhadap peningkatan kefahaman konsep substantif sejarah yang bersifat abstrak melalui penggunaan sumber-sumber dokumen teks sejarah adalah dipengaruhi oleh isi kandungan sumber-sumber tersebut yang telah memaparkan banyak maklumat yang tidak diperolehi di dalam buku teks, dan seterusnya dapat menyumbang kepada peningkatan minat belajar sejarah dalam kalangan murid (Nokes, 2014). Kepelbagaian jenis sumber-sumber dokumen teks sejarah yang digunakan dalam kajian ini seperti carta kronologi, rang undang-undang, enskliopedia, majalah sejarah, poster sejarah, keratan surat khabar didapati mempunyai kaitan dengan konsep-konsep sejarah dalam topik Tamadun Awal Manusia secara langsung mahupun secara tidak langsung. Oleh itu, murid-murid dapat memahami sesuatu konsep substantif sejarah dengan lebih mudah dan mendalam, di samping dapat meningkatkan pencapaian mereka dalam peperiksaan pada peringkat sekolah mahupun pada peringkat nasional secara keseluruhannya. Pemilihan sumber-sumber dokumen teks sejarah yang relevan dan mudah difahami dengan baik oleh murid telah turut menyumbang kepada peningkatan kefahaman konsep substantif sejarah dalam kalangan murid dalam kajian ini. Dapatan ini adalah selaras dengan dapatan kajian Britt, dan Rouet, (2013) serta kajian Merkt, Werner dan Wagner, (2017) yang telah mencadangkan bahawa penggunaan sumber-sumber dokumen teks secara single sources dapat memudahkan proses pemahaman sejarah dalam kalangan murid agar mereka tidak terasa terbeban dengan proses pembelajaran dan seterusnya mengelakkan daripada berlaku percanggahan maklumat yang tidak relevan (Wineburg, 1991; 2001).

\section{Kesimpulan}

Dapatan kajian ini telah menunjukkan bahawa penggunaan sumber-sumber dokumen teks sejarah adalah berkesan untuk meningkatkan kefahaman konsep substantif sejarah dalam kalangan murid Tingkatan Empat. Dapatan ini juga telah membuktikan bahawa penggunaan sumber-sumber dokumen teks sejarah dalam konteks pengajaran dan pembelajaran sejarah dapat melahirkan murid-murid yang mempunyai pengetahuan dan pemahaman yang mendalam terhadap konsep-konsep substantif sejarah yang abstrak yang perlu mereka kuasai dan fahami dalam setiap topik pelajaran sejarah. Kajian ini juga 
diharapkan dapat memberikan sumbangan dalam menyediakan kandungan dan pelaksanaan pengajaran dan pembelajaran sejarah dengan menggunakan satu set koleksi sumber-sumber dokumen teks sejarah bagi topik Tamadun Awal Manusia yang boleh dijadikan panduan dan rujukan kepada para guru sejarah sebagai langkah alternatif kepada kebergantungan sepenuhnya kepada kaedah pengajaran konvensional sedia ada di dalam kelas. Kajian ini juga telah mencadangkan terdapat satu keperluan untuk mengkaji kesan penggunaan sumber-sumber dokumen teks sejarah terhadap kefahaman konsep substantif sejarah dalam tempoh masa yang lebih panjang bagi menentukan sama ada terdapat kesan kekekalan atau tidak pada perubahan kefahaman murid-murid tersebut.

\section{Rujukan}

Abdul Rahim Abdul Rashid. (1999). Kemahiran Berfikir Kritis Merentasi Kurikulum: Pendekatam Pedagogi dan Wawasan Pendidikan Bestari. Shah Alam: Penerbit Fajar bakti.

Abdul Razaq Ahmad, Mohd Mahzan Awang, Ahmad Ali Seman, \& Ramle Abdullah. (2013). The Skills of Using History Textbooks in Secondary School. Asian Social Science, 9(12), 229-236.

Azwan Ahmad, Abdul Ghani Kaneson Abdullah, Mohammad Zohir Ahmad \& Abdul Rahman Abdul Aziz. (2005). Kesan Efikasi Guru Sejarah terhadap Amalan Pengajaran Berbantukan Teknologi Maklumat dan Komunikasi (TMK). Jurnal Penyelidikan Pendidikan, 7, 14-26.

Barton, K.C. (2005). Primary sources in history: Breaking through the myths. Phi Delta Kappan, $86(10), 745-753$.

Berti, A. E., \& Vanni, E. (2000). Italian children's understanding of war: a domain-specific approach. Social Development, 9(4), 478-496.

Breakstone, J., \& Smith, M. (2013). Using Library of Congress Primary Sources for assessment. The TPS Journal, 1(3), 1-8.

Britt, M.A., \& Rouet, J.F. (2011). Research Challenges in the use of multiple documents. International Design Journal, 19(1), 62-68.

Brown, C.A., \& Dotson, K. (2007). A Case Study Using Digital Primary Source Documents. TechTrends, 51(3), 30-37

Bruner, J.S. (1960). The process of education. Cambridge: Harvard University Press.

Campbell, D.T., \& Stanley, J.C. (1963). Experimental and Quasi-experimental Designs for Research. Chicago: Rand McNally.

Cohen, L., Manion, L., \& Morrison, K. (2007). Research Methods in Education (5 ${ }^{\text {th }}$ Edition). London: Routledge Falmer.

Counsell, C. (2000). Historical Knowledge and Historical Skills: A Distracting Dichotonomy. Issues in History Teaching. London: Routldge, 54-71.

Cowgill II, D.A., \& Waring, S.M. (2017). Historical Thinking: An Evaluation of Student and Teacher Ability to Analyze Sources. Journal of Social Studies Education Research, 8(1), 115-145.

Crick, B. \& Porter, A. (1978). Political education and political literacy. Sufflock: Longman.

Cutajar, A. (2013). Towards an 'assessment culture'-implementing assessment for learning in the history classroom. The Educator: a Journal of Educational Matters, 1, 23-45.

Foster, R. (2013). The more things change, the more they stay the same: Developing students thinking about historical changeand continuity. Teaching History, 151, 8-17.

Haenen, J. \& Schrijinemakers, H. (2000). Suffrage, feudal, democaracy, treaty: history's building blocks: Learning to teach historical concepts. Teaching History, 98, 22-29.

Hammond, K. (2014). The knowledge that"flavours" a claim: towards building and assessing historical knowledge on three scales. Teaching History, 157, 18-25.

Haydn, T., Arthur, J. \& Hunt, M. (2001). Learning to Teach History in the Secondary School: A Companion to School Experience. London: Routledge Falmer.

Hazri Jamil. (2003). Teknik mengajar Sejarah. Pahang: PTS Publications \& Distributors Sdn Bhd.

Heater, D.B. (1974). History teaching and political education. London: Occasional Publication.

Hover, S.V., Hicks, D., \& Dack, H. (2016). From Source to Evidence? Teachers' Use of Historical Sources in Their Classrooms. The Social studies, 107(6), 209-217.

Huistra, H., \& Mellink, B. (2016). Phrasing history: Selecting sources in digital repositories. Historical methods, 49(4), 220-229 
Hynd, C.R. (1999). Teaching students to think critically using multiple texts in history. Journal of Adolescent \& Adult Literacy, 42(6), 428-436.

Kaviza, M. (2018, November). Pengetahuan, Kemahiran dan Sikap terhadap Penggunaan Sumber Sejarah di Sekolah Menengah: Perspektif Murid. Kertas kerja yang dibentangkan di Seminar Kebangsaan Majlis Dekan Pendidikan Universiti Awam Malaysia (MEDC 2018), Universiti Sultan Zainal Abidin, Gong Badak, Terengganu.

Lee, P. (2005). Historical literacy: theory and research. International Journal of Historical Learning, Teaching and Research, 5 (1), 29-40.

Levesque, S. (2010). On Historical Literacy: Learning to Think Like Historian. Canadian Issues / Themes Canadiens, 42-46.

Library of Congress. (2019). Using Primary Sources. Retrieved from http://www.loc.gov/tecahers/using primary sources/

Macedo-Rouet, M., Braasch, J.L.G., Britt, M.A \& Rouet, J.F. (2013). Teaching Fourth and Fifth Graders to Evaluate Information Sources During Text Comprehension. Cognition and Instruction, 31(2), 204-226, 204-226.

McCrory, C. (2017). Using a beginning history teachers' consideration of students' prior knowledge in a single lesson case study to reframe discussion of historical knowledge. Revista Electronica Interuniversitaria de Formacion del Profesorado, 20(2), 29-44.

Merkt, M., Werner, M., \& Wagner, W. (2017). Historical thinking skills and mastery of multiple documents tasks. Learning and Individual Differences, 54, 135-146.

Mohd Mahzan Awang, Abdul Razaq Ahmad, \& Nur Syazwani Abdul Talib. (2016). Penggunaan Multimedia Dalam Pendidikan Sejarah Pada Abad Ke-21 dan Hubungannya Dengan Minat Belajar Sejarah. Jurnal Pemikir Pendidikan, 7, 44-56.

Newmann, M. (2001). Primary Sources in Perspective. Journal Educations and Students with Library of Congress Resources.

Nitko, A. J. (2004). Educational Assessment of Students. Ed. Ke-4. Upper Saddle River, NJ: Merril.

Nokes, J.D. (2014). Elementary students' Roles and Epistemic Stances during Document Based History Lessons. Theory \& Research in Social Education, 42, 375-413.

Nunnally, J.C. (1978). Psychometrie Theory $\left(2^{\text {nd }}\right.$ Ed). New York: McGraw Hill.

Omardin Haji Ashaari \& Yunus Muhammad. (1996). Kaedah Pengajaran sejarah. Kuala Lumpur: Utusan Publication \& Distributors Sdn Bhd.

Pusat Perkembangan Kurikulum. (2003) Huraian Sukatan Pelajaran Sejarah Tingkatan Empat. Kuala Lumpur: Kementerian Pendidikan Malaysia.

Pusat Perkembangan Kurikulum. (2015) Dokumen Standard Kurikulum dan Pentaksiran Mata Pelajaran Sejarah Tingkatan Satu. Putrajaya: Kementerian Pendidikan Malaysia

Rantala, J. \& Van Den Berg, M. (2015). Finnish high school and university students' ability to handle multiple source documents in history. Historical Encounters: A Journal of Historical Consciousness, historical cultures and history education, 2(1), 70-88.

Reisman, A. (2012). The "Document-Based Lesson": Bringing Disciplinary inquiry into high school history classrooms with adolescent struggling readers. Journal of Curriculum Studies, 44(2), 233264.

Reisman, A., \& Fogo, B. (2016). Contributions of Educative document based curricular materials to quality of historical instruction. Teaching and Teacher Education, 59, 191-202.

Renuka Ramakrishnan \& Siti Hawa Abdullah. (2012). Penggunaan Sumber Digital Sejarah Dalam Kalangan Guru Sejarah. Seminar Kebangsaan Majlis Dekan, Zon Regency by the Sea Johor Bharu, 7-9 Oktober 2012.

Rogers, R. (2008). Raising the bar: developing meaningful historical consciousness at key stage 3. Teaching History, 133, 24-30.

Seixas, P. (1993). Historical Understanding among Adolescents in a multicultural Setting. Curriculum Inquiry, 23(3), 301-327.

Siti Hawa Abdullah. (2008). Takrif dan Ciri-ciri Pemikiran Sejarah. Pendidikan Sejarah, 9(1), 98-106.

Stoskopf, A \& Bermudez, A. (2008). New Insights Into How Students Learn About The Past: The Pedadogical Triangle of Historical Understanding. Boston: Northeastern University.

Suntharalingam. (1985). Pengenalan Kepada Sejarah. Kuala Lumpur: Marican \& Sons (M). Sdn Bhd.

Van Drie, J., \& Van Boxtel, C. (2003). Developing conceptual understanding through talk and mapping. Teaching History, 110, 27-31. 
Wineburg, S.S. (1991). On the Reading of Historical Texts: Notes on the Breach between School and Academy. American Educational Research Journal, 28(3), 495-519.

Wineburg, S.S. (2001). Historical Thinking and other unnatural acts: Charting the future of teaching the past. Philadelphia: Temple University 